\title{
The Impact of the Enterprise Trans-Province Geographical Diversification on the Corporate Performance of the Manufacturing Industry in Eastern Part of China-Empirical Analysis Based on the Panel Data of the Listed Companies
}

\author{
Zipeng Xu \\ Management School, Jinan University, Guangzhou, China \\ Email:417297237@qq.com
}

How to cite this paper: Xu, Z.P. (2017) The Impact of the Enterprise Trans-Province Geographical Diversification on the Corporate Performance of the Manufacturing Industry in Eastern Part of ChinaEmpirical Analysis Based on the Panel Data of the Listed Companies. Open Journal of Business and Management, 5, 73-82.

http://dx.doi.org/10.4236/ojbm.2017.51007

Received: December 13, 2016 Accepted: December 23, 2016

Published: December 26, 2016

Copyright $\odot 2017$ by author and Scientific Research Publishing Inc. This work is licensed under the Creative Commons Attribution International License (CC BY 4.0).

http://creativecommons.org/licenses/by/4.0/

\begin{abstract}
China market is a divisional market. The distinction between the provinces in China is even larger than the one between some countries abroad. This article studies the relationship between the manufacturing expansion behavior across provinces in the east part of China and the corporate performance. Here two assumptions are presented in this article: 1) there exists a negative correlation between the geographical diversification degree across provinces and the corporate performance; 2) there exists a U-shaped relationship between the geographical diversification degree across provinces and the corporate. By studying the data on 442 China listed companies during the period of 2009 to 2014, it is found that the geographical diversification has a negative impact on the corporate performance when the geographical diversification degree is lower, while the geographical diversification has an active impact on the corporate performance if the geographical diversification degree is higher.
\end{abstract}

\section{Keywords}

The Geographical Diversification, Performance, Divisional Market

\section{Introduction}

The geographical diversification is a kind of the expansion strategy of the corporate. As it is put forward, the relationship between the geographical diversification and the corporate performance has been a focus in strategic management. Does there exist a distinctive relationship between the geographical diversification and the corporate performance? Does there exist a linear relationship or a non-linear relationship between them? In recent ten years, the scholars overseas did a lot of empirical research in order 
to answer the above questions. However, a lot of disputes on this problem still existed.

There was an empirical study demonstrating the positive correlation relationship between geographical diversification and corporate performance [1]; there are also studies proposing a negative correlation relationship between them [2], and some scholars believe that there is no relationship between them [3], even there are studies show that there exists a non-linear relationship between them [4]. This article argues that an important cause to the conflicting result is not adapting the corresponding measurement index according to the feature of the research sample. This article finds that the research adapting the same research sample existed in the past; however it adapts the different types of the geographical diversification measurement index. What's more, there are also some researches adapting the different research samples, however adapting the same types of the measurement index.

This article will have an empirical study on China listed companies in accordance with China's situation. On the one hand, this article will define the corporate performance by ROZ value and Tobin Q value. Since the domestic capital market is at an early stage, many listed companies will have a short-sighted act. For this reason, this article adapts the accounting measurement index and market measurement index comprehensively in order to fully describe the corporate performance. On the other hand, China is a divisional market. The market segmentation creates a larger distinction on the domestic system between regions, and also this divisional market is mainly bounded by provinces. Therefore, the domestic expansion degree across provinces is adapted to define the geographical diversification degree.

This article will do a deep research on the relationship between the geographical diversification and the corporate performance. First of all, this article will propose the targeted measurement index by integrating Chinese context and provide the reference for the related research. Secondly, the empirical result will contribute to clearing up the influencing mechanism on the corporate performance by the geographical diversification under the Chinese context. Finally, the research conclusions in this article will parse how the geographical diversification influences the corporate performance under the Chinese context, and coordinate the conflicting conclusion previously drew.

\section{Literature Review and Hypothesis}

\subsection{Corporate Performance}

When studying the relationship between the geographical diversification and the corporate performance, the scholars mainly measure the corporate performance by using Accounting-based Indicators and Market-based Indicators. Accounting-based Indicators is related to the short-term performance, while Market-based Indicators is related to the long-term performance [5]. Accounting-based Indicators mainly includes: Ration of Sales (ROS), Return on Assets (ROA), Return on Equity (ROE), Sales Growth Rate and so on; and Market-based Indicators mainly includes: Tobin $Q$ value, Earnings per Share (EPS), Cumulative Abnormal Return (CAR) and so on.

\subsection{Geographical Diversification}

The geographical diversification refers to the expansion behavior carried out in other 
regions beyond the geographical scope crossing the birthplace of the corporate. Hereby, the geographical diversification can be divided into the multinational geographical diversification and the inland trans-regional geographical diversification. The multinational geographical diversification and the inland trans-regional geographical diversification have a similar logic, but they have the different geographical scope crossed.

The scholars have measured the geographical diversification by using many kinds of methods. In the previous research, it can be concluded to two kinds called Depth Index and Breadth Index in regard to the geographical diversification measurement. However, some scholars thought that the sole measurement index could not effectively reflect the geographical diversification degree of the corporate and proposed the composite index measurement [6]. However, not only can't the composite index effectively reflect the geographical diversification degree, on the contrary, it restricted people's understanding on the geographical diversification [7]. With the deepening of the research, some of scholars have applied two algorithms called "Entropy Index" and "HerfindahlIndex" to measure the geographical diversification, and the computation formula is as following Table 1. In the computation formula of "Entropy Index", $P i$ is the ratio of the sale at a certain region covering the total sales, and $\operatorname{Ln}\left(1 / P_{i}\right)$ is the weight of this region. The smaller the "Entropy Index" is, the lower the geographical diversification degree is, otherwise, the higher. In the computation formula of "Herfindahl-Index", Si is the proportion of the sales at a certain region. The small the Herfindahl-Index is, the higher the geographical diversification degree is, otherwise, the lower.

\subsection{Research Hypothesis}

The early research shows that there existed a positive correlation relationship between the geographical diversification and the corporate performance. They thought that the geographical diversification can increase the return of the intangible asset, enhance the

Table 1. The common measurement index of the geographical diversification.

\begin{tabular}{|c|c|c|}
\hline Pointer Type & Variable Name & Variable Connotation \\
\hline \multirow{3}{*}{ Depth Index } & FSTS & Overseas sales/total sales \\
\hline & FATA & Overseas assets/total assets \\
\hline & FETE & Number of overseas employee/total number of employee \\
\hline \multirow{3}{*}{ Breadth Index } & OSTS & Number of overseas subsidiary/total number of all subsidiary \\
\hline & NOS & Number of overseas subsidiary \\
\hline & NOC & Number of countries where overseas subsidiary distributed \\
\hline \multirow[b]{2}{*}{ Composite Index } & PSA & $\begin{array}{c}\text { Including three dimensionalities of performance, } \\
\text { structure and attitude }\end{array}$ \\
\hline & Cobweb Model & $\begin{array}{l}\text { Including operation pattern, financial management, } \\
\text { marketing occupation, organization structure, } \\
\text { personnel management, multi-nationalization index }\end{array}$ \\
\hline $\begin{array}{l}\text { Two Types of } \\
\text { Algorithm }\end{array}$ & $\begin{array}{l}\text { Entropy Index } \\
\text { Herfindahl-Index }\end{array}$ & \\
\hline
\end{tabular}

Date source: according to the corresponding references. 
ability of the market, disperse the investment risk, increase the investing opportunity [8]. However, some empirical research show that the negative correlation relationship between the geographical diversification and the corporate performance [9].

Among these, two conflicting opinions respectively are: first, can the corporate risk can be decreased when keeping the same lever profit; second, can the corporate profit be increased [3]. Based on the analysis of Chinese contexts, the author thought that Chinese corporate could not realize the two profits mentioned above when carrying out the tans-provincial geographical diversification at initial stage. On the one hand, for the Chinese enterprises, although there was a certain difference on system among the provinces, there did not exist the distinctive difference on risk among the provinces based on the central government's policy of "stability", so compared with the multinational geographical diversification, Chinese enterprises made a smaller profit in spreading the risk during the period of expansion across provinces. On the other hand, Chinese enterprises needed to invest a certain number of resources (including manpower, materials and financial resources) at the early state of the geographical diversification across provinces. In the short period of time, it was difficult to recover the investment and lift the enterprises' profits, even to some extent, it would cause a negative impact on the enterprises' profits.

The enterprise needed to adapt to the new environment when expanding form one province to another. When the enterprise newly came into a province, it needed to bear Liability of Newness. The enterprise manager would face with a great number of challenges caused by this new business operation, such as purchasing and installing the facilities for production, conducting the personnel allocation, building up the internal management system and the external business network and so on. These challenges would put the new subsidiary into a relative disadvantage, compared with the existing enterprises, and reduce its competitiveness, therefore, we assume that:

H1: A negative correlation relationship existed between the trans-provincial geographical diversification and the corporate performance.

Also some scholars thought that there existed u-shaped relationship between the geographical diversification and the corporate performance. Lu and Beamish made an empirical research on the data of 164 Japanese small and medium-sized enterprises during the period of year 1986 to year 1997, which show a u-shaped relationship between the geographical diversification and the corporate performance [10]. They pointed that most of small and medium-sized enterprises undertook a higher learning cost due to lack of the relevant experience at the first expansion stage. By this time, it was difficult for the small and medium-sized enterprises to make a potential geographical diversification profits. At the second expansion stage, the small and medium-sized enterprises gained enough knowledge on the geographical diversification and market through the experience accumulation, and accordingly improved the enterprise performance.

Ruigrok and Wagner's research on 51 Germany large manufacturing enterprises also show a u-shaped relationship existed between the geographical diversification and the corporate performance [11]. They pointed that Germany enterprises had to come to the countries with a larger discrepancy between cultural difference and systematic logic 
difference to implement the geographical diversification due to the smaller market of the countries around German at the first expansion stage. So there existed a larger management cost at the early expansion stage. Along with the continuous adaptation and study, the enterprise performance later would be gradually improved.

Chinese enterprises might experience these two phases above when having a geographical diversification. That is, reducing the efficiency due to the increase in market heterogeneity and cultural diversity at the early stage. Then, the enterprise will gain much more knowledge on internationalization and market through organizational learning and knowledge expansion, and further get the quality of products and service improved and form a competitive advantage and superior performance. Thus, we assume that:

H2: A u-shaped relationship existed between the trans-province geographical diversification degree and the corporate performance.

\section{Method}

\subsection{Sample}

This article selected some companies listed in Shanghai, Shenzhen Stock Exchange from year 2009 to year 2014 as research samples and made a certain selection on them. Firstly, this study selected the listed companies whose main business belongs to the manufacturing industry based on the industry code of the samples and the new national standard, National Industries Classification (GB/T 4754-2011). Through selecting the manufacturing listed companies as samples, we can control the industry factor and observe the status of the industrial transfer in manufacturing industry in our country. Secondly, this article selected the listed companies registered in the eastern provinces. The manufacturing industry was mainly located in the eastern provinces with a high manpower cost. The industry transfer in the eastern provinces performed a high representative significance. Finally, in order to ensure the integrity of the data information, this study removed some companies with an incomplete disclosure. Ultimately, we obtained 2652 panel data of 442 listed companies. The data in this article come from CSMAR.

\subsection{Variable}

\section{Independent Variable}

Geographical diversification degree. The overseas scholars frequently used the substitution variable of the ratio of the overseas subsidiary earning covering the total earning when measuring the multinational diversification [9]. However, this measuring method could not rule out the semi-finished products export from the parent company to the overseas subsidiary and the buy-back of the finished products [8]. In this kind of emerging market in China, the operation revenue might be influenced by the shortterm act of the management and the fluctuation of the external environment. This measurement may not reflect the degree of the enterprise geographical diversification. Therefore, this article reflected the degree of the enterprise geographical diversification by using the Herfindahl-Index of the registered capital of the subsidiary outside the province. The specific calculation formula is as follows: 
Of which, $\mathrm{Si}$ is the percentage of the registered capital of the subsidiary set up by the listed Company at i province covering the total registered capital of the subsidiary set by this listed company throughout the country. The larger HI is, the higher the enterprise geographical diversification degree, conversely, the smaller.

2. Dependent Variable

Enterprise performance. The usual performance measurement index includes Ration of Sales (ROS), Return on Assets (ROA), Return on Equity (ROE), Economic Value Added (EVA), Tobin $\mathrm{Q}$ value. In the study of the enterprise diversification and performance, Ration of Sales (ROS) is more usually used as the performance measurement index (Grant, 1987; Geringer, 2000). This article adapts two indexes, ROA and Tobin Q value, to measure the enterprise performance. Of which, ROA is defined as the net income divided by the total assets, and Tobin $\mathrm{Q}$ value is defined as the market capitalization divided by the total assets.

3. Control Variable

This article mainly studies the influence of the trans-province diversification on the enterprise performance. In addition to the geographical diversification, other factors may also have the impact on the enterprise performance. By referring to the related research home and abroad, this article put the enterprise scale, the enterprise ages, the Debt ratio, the financial leverage and the ownership concentration to be a control variable. The specific variables and the variables are defined as follow as shown in Table 2.

\subsection{Statistical Approach}

This article adapts the statistical software, Stata12.0, to carry out the data analysis, the descriptive statistics of the variables, the correlation analysis among the variables and the multiple regression analysis. The detailed analytical procedure is as follows: Model 1 and Model 2 make an analysis on control variables, and dependent variables respectively are ROA and Tobin Q value; Model 3 and Model 4 consider the impact on the geographical diversification degree on ROA and Tobin Q value; Model 5 and Model 6 bring into the quadratic component of the geographical diversification and consider the non-linear relationship between the geographical diversification and the corporate performance.

\section{Results}

\subsection{Descriptive Statistics and Correlation Analysis}

The descriptive statistics and correlation analysis result to the variables is as Table 3

Table 2. Name and definition of control variable.

\begin{tabular}{cc}
\hline Variable Name & Variable Definition \\
\hline Enterprise Scale & $\begin{array}{c}\text { Napierian logarithm of total enterprise asset } \\
\text { Enterprise Age } \\
\text { Eebt Ratio }\end{array}$ \\
Financial Leverage duration from the enterprise foundation to the \\
deadline of the statistics \\
Liabilities divided by total assets \\
(Net profit + Income tax expense + Financial cost)/ \\
(Net profit + Income tax expense) \\
Share ratio of the largest shareholder
\end{tabular}


Table 3. The descriptive statistics and correlation analysis of the variable.

\begin{tabular}{|c|c|c|c|c|c|c|c|c|c|c|c|}
\hline & M & SD & 1 & 2 & 3 & 4 & 5 & 6 & 7 & 8 & 9 \\
\hline 1. ROA & 0.04 & 0.01 & 1.00 & & & & & & & & \\
\hline 2. TBQ & 2.56 & 4.75 & $0.087^{\star *}$ & 1.00 & & & & & & & \\
\hline 3. HI & 0.33 & 0.08 & 0.038 & $-0.096^{* *}$ & 1.00 & & & & & & \\
\hline 4. $(\mathrm{HI})^{2}$ & 0.19 & 0.04 & 0.048 & $-0.097^{\star *}$ & $0.955^{* *}$ & 1.00 & & & & & \\
\hline 5. LNA & 21.90 & 1.48 & 0.028 & $-0.478^{\star *}$ & $0.189^{* *}$ & $0.198^{* *}$ & 1.00 & & & & \\
\hline 6. AGE & 14.11 & 25.65 & $-0.072^{\star *}$ & -0.059 & -0.059 & -0.062 & $0.125^{* *}$ & 1.00 & & & \\
\hline 7. Debt ratio & 0.48 & 0.05 & $-0.289^{* *}$ & $-0.171^{\star *}$ & 0.004 & 0.006 & $0.280^{* *}$ & $0.095^{\star *}$ & 1.00 & & \\
\hline 8. FL & 1.51 & 19.82 & -0.023 & -0.038 & -0.033 & -0.034 & 0.012 & -0.003 & $0.068^{*}$ & 1.00 & \\
\hline 9. OC & 34.53 & 207.14 & 0.057 & $-0.083^{\star *}$ & -0.003 & 0.023 & $0.260^{* *}$ & $-0.186^{\star \star}$ & 0.032 & -0.004 & 1.00 \\
\hline
\end{tabular}

$\mathrm{N}=2652 .{ }^{* *} p<0.01,{ }^{*} p<0.05$, Two-tailed Test.

shows. The variable of FL means Financial Leverage and the OC means Ownership Concentration. There is a necessary connection between $\mathrm{HI}$ and $(\mathrm{HI})^{2}$, thus, the correlation coefficient between two reaches up to 0.955 . In addition, the correlation coefficient among other variables is all small. It may be believed that there does not exist the serious multicollinearity among variables. Therefore, the next regression analysis on variables can be conducted to test the relationship between the variables.

\subsection{Hypothesis Testing Result}

As the basic model, Model 1 and Model 2 only consider the impact of the control variable on the corporate performance. Model 3 and Model 4 tested H1. Analytical result shows that there presents a significant negative correlation relationship between the trans-province geographical diversification of the enterprise and TBQ value $(p<0.01)$, and also the negative correlation relationship to ROA, but not significant. Therefore, it can be considered that the trans-province geographical diversification of the enterprise in China has an impact on the corporate performance. Model 5 and Model 6 tested H2. The testing result shows that a u-shaped relationship is presented between the transprovince geographical diversification of the enterprise and TBQ value $(p<0.05)$, and also the $\mathrm{u}$-shaped to ROA, but not significant. Therefore, it can be considered that there is a $\mathrm{u}$-shaped relationship between the trans-province geographical diversification and the corporate performance, that is when the trans-province geographical diversification is lower, there exists a negative correlation relationship between the trans-province geographical diversification and the corporate performance, while the trans-province geographical diversification degree is higher, there exists a positive correlation relationship between two (Table 4).

\section{Conclusions}

The research purpose in this article is to explore the impact of the enterprise transprovince geographical diversification on the corporate performance. For this purpose, this article makes an analysis on the relationship between the trans-province geographical diversification degree and ROA and Tobin $\mathrm{Q}$ value by using the data of the listed 
Table 4. Regression result on the geographical diversification and the corporate performance.

\begin{tabular}{|c|c|c|c|c|c|c|}
\hline & $\begin{array}{c}\text { Model I } \\
\text { ROA }\end{array}$ & $\begin{array}{c}\text { Model II } \\
\text { TBQ }\end{array}$ & $\begin{array}{l}\text { Model III } \\
\text { ROA }\end{array}$ & $\begin{array}{c}\text { Model IV } \\
\text { TBQ }\end{array}$ & $\begin{array}{c}\text { Model V } \\
\text { ROA }\end{array}$ & $\begin{array}{c}\text { Model VI } \\
\text { TBQ }\end{array}$ \\
\hline \multirow[t]{2}{*}{ Corporate Scale } & $0.0440^{* * *}$ & $-1.631^{\star * \star}$ & $0.0441^{* * *}$ & $-1.570^{* * *}$ & $0.0440^{* * *}$ & $-1.578^{* * *}$ \\
\hline & $(0.00622)$ & $(0.0874)$ & $(0.00630)$ & $(0.0882)$ & $(0.00631)$ & $(0.0882)$ \\
\hline \multirow[t]{2}{*}{ Corporate Age } & $-0.0105^{\star * *}$ & -0.00991 & $-0.0105^{* * *}$ & -0.00805 & $-0.0105^{* * *}$ & -0.00750 \\
\hline & $(0.00130)$ & $(0.0183)$ & $(0.00130)$ & $(0.0182)$ & $(0.00130)$ & $(0.0182)$ \\
\hline \multirow[t]{2}{*}{ Asset \&Liability } & $-0.331^{\star * *}$ & 0.317 & $-0.331^{\star * *}$ & 0.320 & $-0.331^{* * *}$ & 0.306 \\
\hline & $(0.0150)$ & $(0.211)$ & $(0.0150)$ & $(0.210)$ & $(0.0150)$ & $(0.210)$ \\
\hline \multirow[t]{2}{*}{ Financial Leverage } & 0.000228 & -0.00224 & 0.000227 & -0.00268 & 0.000232 & -0.00239 \\
\hline & $(0.000418)$ & $(0.00587)$ & $(0.000418)$ & $(0.00585)$ & $(0.000418)$ & $(0.00585)$ \\
\hline \multirow[t]{2}{*}{ First Majority Shareholder } & -0.000102 & -0.00732 & -0.000103 & -0.00784 & -0.000104 & -0.00796 \\
\hline & $(0.000452)$ & $(0.00635)$ & $(0.000452)$ & $(0.00633)$ & $(0.000452)$ & $(0.00632)$ \\
\hline \multirow[t]{2}{*}{ HI } & & & -0.00161 & $-0.844^{* * *}$ & -0.0194 & $-1.909^{* * *}$ \\
\hline & & & $(0.0140)$ & $(0.196)$ & $(0.0373)$ & $(0.521)$ \\
\hline \multirow[t]{2}{*}{$(\mathrm{HI})^{2}$} & & & & & 0.0268 & $1.606^{\star *}$ \\
\hline & & & & & $(0.0521)$ & $(0.729)$ \\
\hline \multirow[t]{2}{*}{ Constant } & $-0.614^{\star * *}$ & $38.52^{* * *}$ & $-0.616^{\star * *}$ & $37.47^{\star * *}$ & $-0.613^{\star * *}$ & $37.68^{* * *}$ \\
\hline & $(0.124)$ & $(1.743)$ & $(0.125)$ & $(1.753)$ & $(0.125)$ & $(1.754)$ \\
\hline$N$ & 2652 & 2652 & 2652 & 2652 & 2652 & 2652 \\
\hline$R^{2}$ & 0.198 & 0.215 & 0.198 & 0.222 & 0.199 & 0.224 \\
\hline Adjusted $R^{2}$ & 0.036 & 0.057 & 0.036 & 0.064 & 0.036 & 0.066 \\
\hline$F$ & $2.82^{* * *}$ & $10.03^{* * *}$ & $2.82^{* * *}$ & $10.15^{* * *}$ & $2.81^{\star * *}$ & $10.18^{* * *}$ \\
\hline
\end{tabular}

$\mathrm{N}=2652 .{ }^{* * *} p<0.001,{ }^{* *} p<0.05,{ }^{*} p<0.1$.

companies in China. We find that there exists a u-shaped relationship between the trans-province geographical diversification degree and the corporate performance; that is to say when the trans-province geographical diversification degree is lower, the transprovince geographical diversification has a negative impact, and a positive impact when higher.

This article believes that the negative impact of the early geographical diversification on the corporate performance is mainly caused by the following two reasons: the first is the liability of foreignness. The liability of foreignness refers to the financial losses en- 
countered by the enterprises due to being unfamiliar to the local environment when newly entering into a certain market [12]. The difference among provinces in China is large, so the enterprise may suffer from "the liability of foreignness" because of being unfamiliar with the local environment when expanding across provinces. The second is the improvement of the management complexity. The trans-province geographical diversification improved the complexity of the management (such as the increased management radius, the slow decision making, etc.). The enterprise at the early stage of the geographical diversification does not possess the management experience across the regions, so the increase of the enterprise management complexity causes the inefficient allocation of the resource, which will finally cause a negative influence to the corporate performance.

The study result in this article shows that the geographical diversification has a positive impact on the corporate performance when the geographical diversification degree of the enterprise gets higher. This result shows that the liability of foreignness can be overcome. This article believes there are two main ways to overcome the liability of foreignness by the enterprise. The first is to accumulate the local knowledge and resource. After a certain period of operation, the enterprise can grasp the local knowledge and resource and improve the corporate performance. The second is to accumulate the trans-regional management experience. By accumulating the trans-regional management experience, the enterprise can improve its own management efficiency and reduce the negative impact on the corporate performance from the increase of the management complexity.

\section{References}

[1] Bausch, A. and Krist, M. (2007) The Effect of Context-Related Moderators on the Internationalization-Performance Relationship: Evidence from Meta-Analysis. Management International Review, 47, 319-347. https://doi.org/10.1007/s11575-007-0019-Z

[2] Denis, D.J., Denis, D.K. and Yost, K. (2002) Global Diversification, Industrial Diversification, and Firm Value. Journal of Finance, 57, 1951-1979. https://doi.org/10.1111/0022-1082.00485

[3] Hennart, J.F. (2007) The Theoretical Rationale for a Multinationality-Performance Relationship. Management International Review, 47, 423-452. https://doi.org/10.1007/s11575-007-0023-3

[4] Capar, N. and Kotabe, M. (2003) The Relationship between International Diversification and Performance in Service Firms. Journal of International Business Studies, 34, 345-355. https://doi.org/10.1057/palgrave.jibs.8400036

[5] Yang, Y. and Driffield, N. (2012) Multinationality-Performance Relationship. Management International Review, 52, 23-47. https://doi.org/10.1007/s11575-011-0095-y

[6] Sullivan, D. (1994) Measuring the Degree of Internationalization of a Firm. Journal of International Business Studies, 25, 325-342. https://doi.org/10.1057/palgrave.jibs.8490203

[7] Ramaswamy, K. (1995) Multinationality, Configuration, and Performance: A Study of MNEs in the US Drug and Pharmaceutical Industry. Journal of International Management, 1, 231-253.

[8] Tallman, S. and Li, J. (1996) Effects of International Diversity and Product Diversity on the Performance of Multinational Firms. Academy of Management Journal, 39, 179-196. https://doi.org/10.2307/256635 
[9] Geringer, M.J., Tallman, S. and Olsen, D.M. (2000) Product and International Diversification among Japanese Multinational Firms. Strategic Management Journal, 21, 51-80. https://doi.org/10.1002/(SICI)1097-0266(200001)21:1<51::AID-SMJ77>3.0.CO;2-K

[10] Lu, J.W. and Beamish, P.W. (2001) The Internationalization and Performance of SMEs. Strategic Management Journal, 22, 565-586. https://doi.org/10.1002/smj.184

[11] Ruigrok, W., Amann, W. and Wagner, H. (2007) The Internationalization-Performance Relationship at Swiss Firms: A Test of the S-Shape and Extreme Degrees of Internationalization. Management International Review, 47, 349-368.

https://doi.org/10.1007/s11575-007-0020-6

[12] Hymer, S.H. (1976) The International Operations of National Firms: A Study of Direct Foreign Investment. MIT Press, Cambridge.

Submit or recommend next manuscript to SCIRP and we will provide best service for you:

Accepting pre-submission inquiries through Email, Facebook, LinkedIn, Twitter, etc. A wide selection of journals (inclusive of 9 subjects, more than 200 journals)

Providing 24-hour high-quality service

User-friendly online submission system

Fair and swift peer-review system

Efficient typesetting and proofreading procedure

Display of the result of downloads and visits, as well as the number of cited articles

Maximum dissemination of your research work

Submit your manuscript at: http://papersubmission.scirp.org/

Or contact ojbm@scirp.org 